\title{
El comienzo de la rivalidad internacional y de la injerencia española en la República Dominicana (1855-1856)
}

\author{
por \\ Luis Alfonso Escolano Giménez \\ Universidad Católica Santo Domingo
}

Esta investigación aborda la compleja coyuntura atravesada por la República Dominicana, como consecuencia de la amenaza de Haití, que invadió de nuevo el territorio dominicano en 1855, y de otras injerencias, si bien más sutiles, por parte de Gran Bretaña, Francia, España y Estados Unidos. Para indagar en el inicio del intervencionismo en la República Dominicana se ha utilizado documentación diplomática española y norteamericana, así como fuentes bibliográficas. El estudio de este proceso permite concluir que la injerencia en la politica dominicana por parte del primer cónsul de España en Santo Domingo acentuó la rivalidad hispanoestadounidense.

Palabras Clave: injerencia en la República Dominicana; relaciones exteriores de la República Dominicana; guerra dominicohaitiana (1855-1856).

\section{INTRODUCCIÓN}

La historia de la República Dominicana entre 1844 y 1861, período denominado por la historiografía dominicana con el nombre de Primera República, viene definida por una serie de factores básicos. El más determinante de ellos es la crisis estructural del nuevo Estado, como consecuencia de su inestabilidad política y su debilidad económica, lo que llevó a los diversos gobiernos de la República a buscar la ayuda de una potencia extranjera, por medio del protectorado o del simple establecimiento de relaciones diplomáticas. El segundo elemento que marcó dicha etapa es la constante amenaza a la independencia dominicana por parte de Haití, materializada en varias invasiones contra su territorio. 
Además de la compleja tesitura interna en que se encontraba inmersa la Isla Española, recaían sobre ella las injerencias externas derivadas de la rivalidad existente entre Estados Unidos, Gran Bretaña, Francia y España, en un área de gran importancia geoestratégica. Las apetencias territoriales del gobierno norteamericano en la bahía de Samaná eran consideradas por las potencias europeas como un peligro cierto, dados los antecedentes anexionistas de aquel país. España, que durante los primeros años se había resistido a involucrarse directamente en las cuestiones que afectaban a su antigua colonia, dio un giro de ciento ochenta grados a esa política de no intervención, y en 1855 decidió reconocer a la República Dominicana, para hacer frente al expansionismo estadounidense en el Caribe.

Los dos principales dirigentes políticos de esta etapa llevaron a cabo numerosos intentos en pos de obtener la protección directa de una potencia extranjera frente a la amenaza que representaba Haití para la independencia dominicana. En efecto, Pedro Santana y Buenaventura Báez, quienes ocuparon la presidencia durante la mayor parte del período 1844-1861, utilizaron recurrentemente, para justificar esta política, el argumento del peligro que suponía Haití, que había controlado todo el territorio insular entre 1822 y 1844 . Buena parte de la historiografía dominicana reciente ha puesto de relieve que la existencia de dicha amenaza no agota las explicaciones de esta tendencia al anexionismo o al protectorado por parte de los principales líderes políticos dominicanos. De hecho, numerosos estudios subrayan las enormes dificultades económicas, que impulsaron a los dos presidentes mencionados a obtener la ayuda de alguna potencia extranjera. También cabe resaltar el importante papel jugado por la rivalidad entre ambos caudillos, quienes apostaban por una u otra potencia en función de sus propios intereses políticos, como un medio en que apoyarse para conquistar el poder o para conservarlo frente al adversario respectivo, y frente a la pequeña burguesía que comenzaba a surgir en el norte del país. Tanto Báez como Santana pertenecían al grupo de los grandes terratenientes del sur y del este que había ostentado el poder desde los tiempos de la colonia.

Así pues, el medio que concibió la vieja clase dirigente para conservar su tradicional poder político y económico fue la obtención del apoyo de una potencia extranjera, que además le permitiese sanear la precaria situación financiera que el Estado dominicano venía padeciendo desde sus orígenes, y defenderse de las agresiones de Haití. El objetivo de aferrarse al poder, aun a costa de enajenar parcial o totalmente la soberanía dominicana por medio del protectorado o la anexión, condujo a la realización de numerosas gestiones en tal sentido por parte de los gobiernos de Santana y Báez. Dicha rivalidad interna, sin embargo, no habría alcanzado la repercusión que finalmente tuvo 
fuera de sus fronteras, de no haber sido porque coincidió con otra rivalidad a mayor escala, la que existía entre Estados Unidos y los países europeos con más intereses en el Caribe -España, Gran Bretaña y Francia-, así como la que mantenían estos países entre sí. La política seguida por España evolucionó desde una inhibición casi total al comienzo del período hasta la anexión de Santo Domingo en 1861. No cabe duda de que el objetivo de cerrar el paso a Estados Unidos influyó, de manera determinante, sobre la política seguida por los diversos gobiernos españoles hacia la República Dominicana.

En este contexto se inscribe el episodio que la historiografía dominicana denomina «matrícula de Segovia», en alusión a Antonio María Segovia, primer cónsul de España en Santo Domingo, quien trató de obstaculizar de la forma más expeditiva posible el acercamiento entre los gobiernos dominicano y estadounidense. Para ello, el diplomático español se valió de la aguda animadversión que enfrentaba a los partidarios del presidente Santana con los del expresidente Báez, y apoyó a éste en su lucha contra aquél, a fin de alcanzar el objetivo que se había trazado, lo cual consiguió Segovia por medio de un relevo en la primera magistratura.

En medio de numerosas intrigas diplomáticas y de la agitación política reinante en el país, Santana se dirigió al agente comercial de Estados Unidos en Santo Domingo, con objeto de transmitirle su interés por reanudar las negociaciones para la firma de un tratado entre ambos gobiernos. Como estudiamos en otro trabajo, las mismas habían quedado interrumpidas en 1854, debido a la intervención de los cónsules de Gran Bretaña y Francia para entorpecer dicho tratado. Cabe subrayar que el gabinete de Madrid contemplaba tal posibilidad como un peligro, pues temía que la presencia norteamericana en territorio dominicano fuera sólo un primer paso para lanzarse sobre Cuba y Puerto Rico ${ }^{1}$.

Por otro lado, la mediación francobritánica no pudo impedir la última invasión de Haití contra la República Dominicana, en 1855-1856, que se saldó con un nuevo fracaso haitiano, pero demostró la ineficacia de la labor diplomática confiada a las dos naciones europeas. Ello incidió también en la búsqueda de alternativas a esa vía por parte del ejecutivo de Santo Domingo, que intentó «mantener abierto en todo momento el mayor número posible de opciones», como analizamos en la mencionada investigación. Por consiguiente, cabe afirmar que el régimen de Santana «no dudó en jugar a dos bandas en la negociación de sendos tratados», aunque conocía el interés de España por impedir la penetración estadounidense ${ }^{2}$.

\footnotetext{
${ }^{1}$ Escolano Giménez, 2011: 278-279.

2 Ibidem: 278.
} 
Además, hay que tener en cuenta el cambio de la política desarrollada por Francia y Gran Bretaña con respecto al gabinete de Washington. Así pues, la necesidad de no enfrentarse abiertamente, y en solitario, a la actuación de los representantes de la potencia norteamericana influyó mucho en el papel que debían desempeñar los agentes de España, para no arriesgar la seguridad de Cuba y Puerto Rico.

No obstante, llama la atención que los principales problemas surgieran a raíz de la intervención en la política interna dominicana a favor del expresidente Buenaventura Báez -quien gobernó entre 1849 y 1853-, por parte del primer cónsul de España en Santo Domingo, Antonio María Segovia. En efecto, las repercusiones de la matrícula abierta para la inscripción de los ciudadanos españoles en la legación diplomática dieron pie a que la gestión de Segovia haya sido considerada, por la historiografía dominicana en su conjunto, como uno de los más cumplidos ejemplos de la injerencia extranjera en los asuntos del país.

Esta apreciación resulta muy llamativa, sobre todo si se toman en consideración otros episodios semejantes, como las maniobras francobritánicas contra el tratado dominicoestadounidense en 1854, o la mediación de los tres cónsules europeos entre Báez y Santana en 1856, tras la caída de este último y su relevo por aquél, durante los cuales la presión externa se hizo sentir de forma similar. Tal vez lo que más sorprenda en el caso de la llamada «matrícula de Segovia» es que se trata de una injerencia proveniente de España, país del cual no cabía esperar una política tan agresiva en defensa de sus propios intereses, debido a su condición de potencia media. Frente a las críticas de todo género vertidas por unos y otros contra Segovia, el general De la Gándara, que suele tener un juicio ponderado y poco proclive a prodigar alabanzas desmedidas, describe a quien fue primer cónsul de España en Santo Domingo como «un hombre muy hábil y experto», e «individuo benemérito» del cuerpo consular español ${ }^{3}$.

\section{La Última invasión de Haití contra la República Dominicana}

En noviembre de 1855 los haitianos lanzaron una nueva invasión contra el territorio dominicano, a la que en parte «contribuyó la actuación de Francia e Inglaterra», a juicio de Jimenes Grullón. En efecto, los cónsules de ambos países «hicieron ver al emperador haitiano el peligro que significaba para la independencia de Haití» que la República Dominicana cayese en poder de Estados Unidos, «como consecuencia de las negociaciones de Santana con

\footnotetext{
3 De la Gándara Navarro, 1975, vol. 1: 111.
} 
Washington». En cualquier caso, Soulouque estaba convencido de que «las promesas francoinglesas de garantizar la independencia dominicana eran puras palabras» ${ }^{4}$. Así pues, el emperador decidió poner en práctica el principio de la «isla una e indivisible», recogido en la constitución haitiana, algo que ya habían intentado tanto sus predecesores como él mismo, siempre con idéntico resultado desfavorable.

Esta nueva ofensiva militar podría considerarse de índole semejante a las pasadas campañas, puesto que se trataba de obtener una importante expansión territorial a costa de un vecino en teoría más débil, pero la mayor parte de los autores coinciden en señalar también otro factor: el temor de Haití a Estados Unidos, que se basaba en el hecho de que eran una potencia esclavista y su presencia en territorio dominicano podría amenazar la independencia haitiana ${ }^{5}$.

En fechas previas a la invasión el gobierno norteamericano se había mostrado muy interesado en reactivar la negociación de un tratado con la República Dominicana, según lo indicó el secretario de Estado, William L. Marcy, a Jonathan Elliot, agente comercial de Estados Unidos en Santo Domingo. En efecto, el 5 de octubre de 1855 aquél informó a Elliot de que el Departamento de Estado no había recibido ninguna copia de las modificaciones introducidas por el Congreso dominicano en el proyecto anterior, y por consiguiente no podía formarse opinión en cuanto a si las mismas debían «ser consideradas aceptables para pedir la aprobación del presidente y del Senado» estadounidenses ${ }^{6}$.

Sin embargo, en otra comunicación dirigida el 9 de octubre al mencionado agente comercial, Marcy dejó clara la negativa del ejecutivo de Washington a aceptar la propuesta de modificación del artículo tercero. La razón de esa negativa estaba basada, obviamente, en el color de piel de muchos dominicanos, ya que la nueva redacción de dicho artículo planteaba «colocar a los dominicanos de todas clases [...] en pie de igualdad con los ciudadanos» de Estados Unidos, cuando estuviesen en territorio norteamericano. En su despacho del 5 de octubre Marcy también llamó la atención de Elliot, acerca del artículo que «proponía conceder ciertos privilegios» a Estados Unidos con respecto al depósito de carbón en Samaná para uso de sus barcos. El secretario de Estado le recordó que en 1854 «los dominicanos fueron disuadidos de acceder» a los deseos de Washington en este asunto, debido en parte a aprensiones «infundadas» acerca de que los norteamericanos pretendían convertirse «en propietarios de un territorio» en ese lugar de la costa dominicana. A conti-

\footnotetext{
4 Jimenes Grullón, 1980, vol. 1: 67.

${ }^{5}$ Moya Pons, 1998: 180.

${ }^{6}$ Lockward, 1987: 280-281.
} 
nuación, Marcy le insistió en la conveniencia de que la estación carbonera se estableciera en la mencionada bahía, por tratarse del punto más idóneo para tal fin, e incluso afirmó que el ejecutivo de Washington no podría «aceptar otro lugar» que no fuese Samaná ${ }^{7}$.

Las claras instrucciones del secretario de Estado a Elliot no dejaban lugar a dudas: si no se le concedía la ansiada base en Samaná, Estados Unidos no firmaría ningún tratado con la República Dominicana. La mera posibilidad de que los norteamericanos pusieran el pie en la isla era pretexto más que suficiente para que Soulouque ordenase la temida invasión, algo que siempre se cernía como una amenaza sobre la República Dominicana, por lo que el gobierno de ésta no se encontraba desprevenido y supo reaccionar con rapidez ante un ataque masivo, en el que treinta mil soldados enemigos cruzaron la frontera por tres puntos diferentes al mismo tiempo. Las tres columnas penetraron por el norte, el centro y el sur, pero la movilización general decretada por las autoridades permitió frenar el avance de las tropas haitianas. Santana coordinó las operaciones militares que hicieron posible la victoria de las armas dominicanas en dos importantes acciones, las de Santomé y Cambronal. Esta contraofensiva surtió efecto, y las tropas del emperador se retiraron hacia la frontera, hasta donde fueron perseguidas por los dominicanos, quienes durante las semanas siguientes obtuvieron nuevos triunfos en el norte ${ }^{8}$.

La guerra que tuvieron que librar los dominicanos para defender y consolidar su independencia duró cerca de doce años, desde marzo de 1844 hasta enero de 1856. En efecto, esta fecha marca el fin de la larga lucha que sostuvo la República Dominicana contra las sucesivas agresiones de Haití 9 . Después de dichas victorias, durante el mes de febrero hubo tan sólo algunas escaramuzas, con lo que los dominicanos llegaron en marzo de 1856 a la situación de statu quo posbélico en una posición bastante ventajosa ${ }^{10}$.

Jimenes Grullón se pregunta si cabe interpretar la participación del pueblo en tales luchas como una señal de que «la clase media y la clase obrera del país respondían al sentimiento de dominicanidad», a lo que responde que este sentimiento se encontraba todavía «en proceso de germinación». En su opinión, dichas clases sociales conservaban viva «la hostilidad hacia Haití, nacida de las recientes guerras y de la labor de enajenación que realizó al respecto [...] la clase dominante». El mencionado autor sostiene que esta última «obedecía a la mentalidad colonialista», por lo que «gestionaba el protectorado o la ane-

\footnotetext{
7 Ibidem: 281-282.

8 Moya Pons, 1998: 180.

${ }^{9}$ Hungría Morell, 1982: 39.

${ }^{10}$ Incháustegui Cabral, 1965: 40.
} 
xión a cualquier potencia»y, mientras tanto, «mantuvo una constante prédica antihaitiana que tenía visible raíz en motivaciones económicas, mezcladas con elementos racistas». En conclusión, «para esta clase, caer de nuevo bajo el dominio de Haití significaba la pérdida de sus bienes y privilegios y quedar a la merced de exesclavos africanos» ${ }^{11}$.

Esta interpretación parece no tomar en cuenta el hecho innegable de que, aparte de la lógica hostilidad entre ambos pueblos, producto de los frecuentes conflictos bélicos y de la hipotética labor alienante desarrollada por las clases dirigentes, existen también otros factores de carácter político e incluso idiosincrásico que hacían poco menos que inviable la unión de las dos naciones en que se divide la isla, desde sus notables diferencias en lo relativo a costumbres y lengua, hasta sus creencias y/o prácticas religiosas.

\section{Llegada del cónsul de España a Santo Domingo}

El 27 de diciembre de 1855, con la guerra aún en su punto álgido, llegó a la capital dominicana Antonio María Segovia, primer cónsul de España en Santo Domingo, quien recibió poco después el encargo de conferir a Santana la gran cruz de Isabel la Católica ${ }^{12}$. Antes de la llegada de Segovia a Santo Domingo, el ministro de Estado, Juan de Zabala, dio instrucciones al agente comercial de España en esa ciudad, Eduardo San Just, sobre cómo debía actuar frente a la grave crisis en que estaba sumida la República Dominicana, a raíz de la invasión haitiana. En su comunicación, Zabala acusó recibo del despacho en que San Just le había informado de la situación política reinante, por haber rehusado Francia y Gran Bretaña «prestar su garantía para la celebración de un tratado con Haití». Acto seguido, el ministro indicó que, «conviniendo mucho a España la conservación y prosperidad» de la República Dominicana, y que no la perturbasen los haitianos, el agente español debía «intimar con el cónsul de Francia, y obrar de acuerdo con él, evitando en lo posible» que lo recelase el representante del ejecutivo de Londres, el cual, como protector de la raza negra, favorecía a Soulouque ${ }^{13}$.

El ministro de Estado expuso además su opinión de que el gobierno británico estaba jugando un doble papel en la cuestión dominicohaitiana, ya que

11 Jimenes Grullón, 1980, vol. 1: 67-68.

12 Carta de Isabel II a Santana, Madrid, 20 de noviembre de 1855, Archivo General de la Administración, Alcalá de Henares (AGA), Asuntos Exteriores, legajo 54/5224, carpeta 5.

${ }_{13}$ Carta de Zabala al agente comercial de España en Santo Domingo, Madrid, 3 de diciembre de 1855, AGA, Asuntos Exteriores, legajo 54/5224, carpeta 5. 
«por no ponerse en pugna con las demás naciones europeas», había «aparentado desear la paz entre los dos estados de esa isla, deseando y aun quizás atizando siempre la discordia». Zabala sostuvo que Francia, por el contrario, había obrado siempre de buena fe, y los intereses de España estaban «en ese punto muy en consonancia» con los de dicho país, razón por la cual el gobierno español seguiría la política francesa en la República Dominicana. Estas instrucciones llegaron a Santo Domingo con mucho retraso, el 23 de junio de 1856, por lo que no fue posible su puesta en práctica cuando las circunstancias resultaban más apremiantes. Por otra parte, a fin de aumentar el entendimiento existente con el ejecutivo de París, Zabala se dirigió también al representante de España en esa capital, a quien recomendó que avivase el celo del gobierno francés y lo predispusiera en favor de los intereses españoles ${ }^{14}$.

El 8 de diciembre los cónsules de Gran Bretaña y Francia en Puerto Príncipe enviaron al ministro haitiano de Relaciones Exteriores una nota de protesta, de la cual Segovia envió copia al ministro de Estado, en que manifestaban lo siguiente:

Los abajo firmantes, [...] informados de los preparativos militares que se hacen notar desde hace algún tiempo en el Imperio de Haití, han recibido de sus gobiernos la orden de comunicar [...] cuán penoso les sería ver interrumpirse la obra de la mediación entre las dos partes de la isla por un reinicio de las hostilidades, que los habitantes de las provincias del este no han provocado nunca, y cuya iniciativa ha sido tomada demasiado a menudo por el gobierno haitiano.

[...] Sería contrario a todas las reglas del derecho internacional [...] recurrir al empleo de la fuerza, antes de haber agotado todos los medios de conciliación que las potencias mediadoras se ocupan de concertar, y que conservan la esperanza de hacer aceptar.

Inglaterra y Francia no podrían, pues, ver con indiferencia una invasión del territorio dominicano mientras no hayan retirado su mediación ${ }^{15}$.

Esta protesta diplomática, en la que las potencias mediadoras llegaron también a amenazar a Haití con un bloqueo naval, no surtió efecto alguno y, una vez más, la invasión tuvo que ser rechazada por las tropas dominicanas sin apoyo exterior de ninguna clase.

14 Idem.

15 Carta de Segovia al ministro de Estado español, Santo Domingo, 7 de enero de 1856, Archivo del Ministerio de Asuntos Exteriores y de Cooperación, Madrid (AMAE), Política Exterior, República Dominicana, legajo H 2374 (la traducción es nuestra). 
En circunstancias tan adversas, Santana llegó sin duda a la conclusión de que «el fallo de ingleses y franceses en evitar este ataque, revelaba el escaso valor de sus promesas», lo cual le concedía una mayor libertad de acción con respecto a las negociaciones encaminadas a la firma de un nuevo tratado entre la República Dominicana y Estados Unidos. Es muy probable, pues, que de no haber fracasado la mediación francobritánica, el gobierno dominicano hubiese dilatado o incluso suspendido dichas negociaciones, con el fin de no enemistarse con las dos potencias mediadoras. Sin embargo, después de su triunfo frente a los haitianos ya no tenía por qué temer al hipotético fin de una labor de apaciguamiento que se había mostrado incapaz de frenar a Soulouque. Por ello, Santana decidió dar un giro a las negociaciones que venía manteniendo con el agente Elliot, a fin de «lograr un tratado comercial que incluyera una cláusula de alquiler de la bahía de Samaná»» a Estados Unidos ${ }^{16}$, como medio de asegurarse el apoyo de este país frente a la continua amenaza haitiana.

Aunque había derrotado a sus vecinos, Santana «consideró que el peligro haitiano persistía y sólo podía desaparecer» en caso de obtener «el protectorado o la anexión» a alguna potencia, según Jimenes Grullón. Dado que las tres naciones europeas con más intereses en el área se habían mostrado reticentes ante este planteamiento, la elección sólo podía recaer en Estados Unidos, cuyo gobierno estaba entonces «en franca política expansionista». Además, cabe afirmar que un tratado con ese país «abría las puertas a otros que bien podían implicar la entrega de la República» a los norteamericanos ${ }^{17}$.

Esta posibilidad, cada vez más próxima, no escapaba a las autoridades españolas, tal como se aprecia en la comunicación que dirigió Zabala a San Just el 4 de diciembre, en la cual le advirtió de que «el estado de desasosiego» en que se encontraba la República Dominicana podría llevar a sus gobernantes a buscar «apoyo en la Unión, haciendo en cambio concesiones y poniéndose acaso bajo el protectorado de Washington». Por este motivo, el ministro le indicó que debía obrar de acuerdo con el cónsul de Francia, y «seguir la política de esta nación tan interesada como nosotros en favor de Santo Domingo» ${ }^{18}$.

Sin embargo, estas instrucciones también llegaron a su destino demasiado tarde, el 23 de junio de 1856, cuando la situación había cambiado de forma considerable. El ministro de Estado comunicó a Segovia que los gobiernos de Gran Bretaña y Francia habían acordado «oponerse a la invasión de Santo

${ }^{16}$ Hauch, 1996: 110.

17 Jimenes Grullón, 1980, vol. 1: 68.

18 Carta de Zabala al agente comercial de España en Santo Domingo, Madrid, 4 de diciembre de 1855, AGA, Asuntos Exteriores, legajo 54/5224, carpeta 5. 
Domingo por los haitianos; ya estableciendo el bloqueo de la isla, y constituyéndose árbitros en la contienda; ya por otros medios si esto no bastare». A continuación, Zabala señaló que el gobierno español debía participar en esa empresa, «mas de cualquier manera que se lleve a cabo, en nada tomará la España la iniciativa, de modo ostensible», por lo que instruyó a Segovia para que actuase siempre de acuerdo con los cónsules de Gran Bretaña y Francia. El ministro también le indicó que, en todo lo que «las instrucciones de sus respectivos gobiernos» dejaran «al arbitrio de los cónsules», debía procurar inclinarse «si fuere necesario, a llevar las cosas hasta el último trance», y a todo aquello que, a su entender, conviniese más a los intereses de España y al objeto que se había propuesto alcanzar. Zabala reconoció que España estaba más interesada que dichas naciones «en la consecución de este objeto», pero insistió en la necesidad de que Segovia ajustara «estrictamente su conducta» en todo a la de los otros cónsules ${ }^{19}$.

Como es obvio, el «objeto» al que se refería Zabala no podía ser otro que impedir, o cuando menos obstaculizar, el acercamiento de Santana a Estados Unidos. Así lo aseguraba el ministro cuando informó al capitán general de Cuba de las gestiones que había llevado a cabo por medio de los representantes de España en París y Londres, a fin de que expusieran a aquellos gobiernos «la apurada situación de los dominicanos, el fruto que de ella» podía sacar Estados Unidos, y lo conveniente que sería a los intereses europeos el concertarse "para impedir la invasión del emperador Soulouque». Acto seguido, Zabala señaló que los gobiernos de Gran Bretaña y Francia estaban «dispuestos a oponerse a la expedición», y además verían con satisfacción que España estuviese «a su lado en esta empresa». El ministro dio orden al gobernador de que enviara a Santo Domingo fuerzas navales suficientes «para concurrir al bloqueo», o a cualquier otra medida que fuese necesario adoptar ulteriormente. Dichas fuerzas obrarían «de consuno con las de las mencionadas naciones», siempre con el propósito de «evitar que los de Santo Domingo, desesperando de resistir por sí solos a los haitianos», aceptaran la protección de Estados Unidos, que tal vez fuese con este objeto el oculto promotor del conflicto entre ambos países ${ }^{20}$.

Sin embargo, pocos días más tarde el ministro de Estado recibió un telegrama del encargado de negocios de España en Londres, por medio del cual éste le comunicó que «después de la completa derrota de los haitianos», Cla-

${ }_{19}$ Carta de Zabala al cónsul de España en Santo Domingo, Madrid, 31 de enero de 1856, AGA, Asuntos Exteriores, legajo 54/5224, carpeta 5.

${ }^{20}$ Carta de Zabala al gobernador de Cuba, Madrid, 31 de enero de 1856, AMAE, Política Exterior, República Dominicana, legajo H 2374 (minuta). 
rendon consideraba «inútil la mediación de España en Santo Domingo» ${ }^{21}$. Esta noticia, que por una parte resultaba tranquilizadora, no parecía traer consigo nada bueno para los intereses españoles, como pronto supo el gobierno por conducto de Segovia, quien avisó de que las gestiones del agente de Washington se habían hecho «cada día más apremiantes» para obligar al gobierno dominicano a la firma de un tratado con el norteamericano. No obstante, la peor noticia para España era que los cónsules de Francia y Gran Bretaña no habían hecho nada para estorbarlo ${ }^{22}$, si bien la opinión del agente comercial de Estados Unidos sobre este punto era algo más matizada que la de Segovia.

En efecto, el 16 de enero de 1856 Elliot aseguró a Marcy que el gobierno de Santana había renunciado «a las enmiendas insertadas en el tratado», de modo que éste sería modificado y firmado lo antes posible, cuando el presidente regresara de Azua. El agente comercial anunció que se aprobaría «virtualmente en la misma forma propuesta por William L. Cazneau», el agente especial enviado a tal fin por el ejecutivo de Washington, pero que las autoridades dominicanas preferían «hacer una convención separada con respecto a Samaná» cuando el país estuviese más tranquilo, ya que los haitianos acusaban «públicamente a Santana de querer entregar la isla a los americanos». Por último, Elliot señaló que el cónsul de España se había unido a los de Gran Bretaña y Francia en la oposición a que se concediera una estación naval a los estadounidenses ${ }^{23}$. De ello cabe deducir que ambos países sólo se oponían a la cesión de una parte del territorio dominicano a Estados Unidos, pero no a la firma del tratado.

El cónsul de España, según sus propias palabras, se encontraba «sin instrucciones algunas» con que hacer frente a esta inesperada situación, y acusó a los miembros del gobierno dominicano partidarios del tratado de haberse dejado sobornar por Elliot. En esa tesitura tan complicada, Segovia recibió la orden de condecorar a Santana con la gran cruz de Isabel la Católica, por lo que se dirigió al presidente con objeto de comunicarle la noticia, y aprovechó también para expresarle su preocupación por los acontecimientos que tenían lugar en la capital mientras él continuaba en Azua. El cónsul aseguró que, después de recibir la contestación de Santana, había «logrado paralizar por de pronto estos manejos», aunque no respondía «del resultado definitivo» de los mismos, en caso de no recibir instrucciones detalladas desde Madrid. A

${ }^{21}$ Telegrama de Comyn al ministro de Estado español, AMAE, Política Exterior, República Dominicana, legajo H 2374 (esta comunicación se recibió en Madrid el 3 de febrero de 1856).

${ }^{22}$ Carta de Segovia al ministro de Estado español, Santo Domingo, 7 de febrero de 1856, AMAE, Política Exterior, República Dominicana, legajo H 2374.

${ }^{23}$ Welles, 1981, vol. I: 158-159. 
juicio de Segovia, la condecoración concedida al presidente había surtido un gran efecto, por lo que estaba "persuadido de que por medios semejantes, y por la franca reunión de España a la mediación», lograrían «inutilizar los esfuerzos» de sus enemigos ${ }^{24}$.

El agente de España llamó la atención de Santana sobre las graves consecuencias que tendría dar un paso en la dirección que el gobierno dominicano parecía haber tomado, y le escribió en estos términos:

Me atrevería a suplicar a V. que diese sus órdenes para suspender las negociaciones que parece van a entablarse con el agente de los Estados Unidos para fijar los preliminares de un tratado. Es cosa desusada, irregular, anómala, inexplicable y hasta debe ser sospechosa para V., que haya tanta prisa para tratar en su ausencia; y esto hallándose la República en estado de sitio [...]. ¿Y no es una verdadera torpeza diplomática cuando no otra cosa peor el entrar en tratos en las actuales circunstancias? [...].

La negociación en sí misma no sólo no es en mi juicio conveniente para la República Dominicana sino que puede serle altamente perjudicial y desde luego hará que Inglaterra y Francia retiren su mediación con gran contentamiento de Soulouque y de algún otro sujeto que no me atrevo a nombrar. No hablo aquí [...] como encargado de negocios de España: mi gobierno no ha podido prever que apenas deshechos por la prudencia de V., del Senado, y de otras personas discretas las marañas de Cazeneau (sic), se habían de renovar tan pronto tales intrigas [...]. Por consecuencia, mi gobierno ni me ha dado ni ha podido darme instrucciones para caso tan imprevisto [...]. La guerra civil y la guerra extranjera seguirían inmediatamente a estas negociaciones y [...] los enemigos personales de V. se aprovecharían diestramente de ese poco meditado paso causándonos a todos graves conflictos [...]. Veo que la mayor parte de sus ministros [...] se me muestran en ese punto muy reservados ${ }^{25}$.

Santana respondió a Segovia que podría comunicarse confidencialmente sobre esta materia con el vicepresidente de la República y con el ministro de la Guerra, mientras él se encontrara ausente ${ }^{26}$. Respecto a sus relaciones con los diferentes miembros del gobierno dominicano, el cónsul señaló a Zabala

${ }^{24}$ Carta de Segovia al ministro de Estado español, Santo Domingo, 7 de febrero de 1856, AMAE, Política Exterior, República Dominicana, legajo H 2374 (el texto en cursiva aparece subrayado en el documento).

${ }_{25}$ Carta de Segovia a Santana, Santo Domingo, 28 de enero de 1856, AMAE, Política Exterior, República Dominicana, legajo H 2374 (copia, adjunta al despacho anterior. El texto en cursiva aparece subrayado en el documento).

${ }_{26}$ Carta de Santana a Segovia, cuartel general de Azua, 2 de febrero de 1856, AMAE, Política Exterior, República Dominicana, legajo H 2374 (copia, también adjunta al mismo despacho). 
que de los dos plenipotenciarios nombrados para negociar el tratado con Estados Unidos, había «atraído a la devoción de España» a uno de ellos, que era Ignacio de Castro. El otro, Tomás Bobadilla, presidente del Senado, fue definido por Segovia como un «mulato astuto, doble, codicioso y venal», que era «enteramente adverso» a España aun cuando él le perjuraba lo contrario, y lo mismo sucedía con el ministro de Hacienda, Manuel Joaquín Delmonte. Sin embargo, aseguró que lo peor era que aunque ya contaba «con la mayoría del gabinete incluso el presidente mismo», tenía en contra la circunstancia de que el ejecutivo de Washington prometía «recursos de todas clases prontos y eficaces en la apuradísima situación de esta República». Por su parte, el gobierno español no había podido «hacer otro tanto», al menos hasta ese momento, lo cual debilitaba su influencia en gran medida ${ }^{27}$.

A propósito de los supuestos recursos prometidos al gobierno dominicano por parte del estadounidense, García cita a Théophile Guérin, quien en su Biographie de l'empereur Soulouque afirma que Cazneau «se había presentado en Santo Domingo ofreciendo a la joven República, en nombre de la Unión, oro californiano para retirar de la circulación la prodigiosa» cantidad de papel moneda existente, a cuya emisión «no cesaba de recurrir ese país para hacer frente a su administración interior» ${ }^{28}$.

\section{LA CUESTIÓN DEL TRATADO DOMINICONORTEAMERICANO}

Zabala escribió a Segovia que se había dirigido a los agentes de España ante los gobiernos británico y francés, para poner en conocimiento de aquéllos «el descuido» de los cónsules de ambas naciones en Santo Domingo, frente a la determinación del gobierno dominicano de «celebrar un tratado de alianza» con el estadounidense ${ }^{29}$. El ministro de Estado también había ordenado a los representantes de España en Londres y París que lo comunicaran a los ejecutivos de Gran Bretaña y Francia, para ver si se lograba que éstos diesen «más precisas y eficaces instrucciones a sus cónsules», o avivaran «al menos su celo para el mejor cumplimiento» de las que ya debían haber recibido. En cuanto a la postura que Segovia tenía que mantener, el ministro le recomendó

${ }^{27}$ Carta de Segovia al ministro de Estado español, Santo Domingo, 7 de febrero de 1856, AMAE, Política Exterior, República Dominicana, legajo H 2374 (el texto en cursiva aparece subrayado en el documento).

${ }_{28}$ García, 1968, vol. 3: 161-162.

${ }^{29}$ Carta de Zabala al cónsul de España en Santo Domingo, Madrid, 22 de marzo de 1856, AGA, Asuntos Exteriores, legajo 54/5224, carpeta 6. 
actuar por todos los medios a su alcance para impedir la firma del tratado dominiconorteamericano, que era «tan contrario» a los intereses españoles. Más aún, Zabala le insistió en que asegurase al gobierno dominicano que los de Francia y Gran Bretaña estaban «animados de los mismos sentimientos que el de España» ${ }^{30}$.

Las últimas palabras del ministro coinciden con las que escribió ese mismo día al plenipotenciario de España en París, en las cuales expresó la satisfacción del gobierno español al conocer «la conformidad de miras», así como las ideas y los «planes políticos tan favorables a los intereses de España», que los gobiernos británico y francés tenían «sobre los negocios de América, y singularmente sobre los de Nicaragua y Santo Domingo». Dicho agente había transmitido a Zabala esta tranquilizadora información después de entrevistarse con Clarendon y Walewski, responsables de la política exterior de Gran Bretaña y Francia, respectivamente ${ }^{31}$.

Con relación a las incursiones de los filibusteros estadounidenses en Centroamérica, el gobernador de Puerto Rico ya había dado noticia al gobierno español de estos hechos. El funcionario afirmó que la situación en el istmo era cada día más grave, si se tenía en cuenta el resultado que podía «ofrecer la conquista de Nicaragua por Kinney y la de Costa Rica por Walker». El gobernador de Puerto Rico aseguró además que, según informaciones fidedignas procedentes de Estados Unidos, se preparaban «a marchar americanos para ponerse a las órdenes de los dos expresados aventureros y engrosar sus filas con el fin de seguir sus conquistas». A su juicio, las mismas pondrían las posesiones españolas «en un estado angustioso, más particularmente a la isla de Cuba», a la cual se encaminaban sus planes ${ }^{32}$.

De todo ello puede deducirse que el creciente expansionismo norteamericano era visto como una verdadera amenaza contra la más preciada posesión de España, por parte de sus autoridades en las Antillas. No obstante, las actividades desestabilizadoras de esos «aventureros» tenían en realidad por objetivo directo obtener el control de países como Nicaragua, Costa Rica o incluso, en cierto modo, la República Dominicana.

E1 22 de marzo de 1856 el agente comercial de Estados Unidos en Santo Domingo dirigió tres despachos a Marcy, en los cuales le informó de que no había podido «hacer nada acerca de Samaná», debido a que «la oposición de los

\footnotetext{
${ }^{30}$ Idem.

${ }^{31}$ Carta de Zabala al plenipotenciario de España en París, 22 de marzo de 1856, AMAE, Política Exterior, República Dominicana, legajo H 2374 (minuta).

32 Carta del gobernador de Puerto Rico al ministro de Estado español, 29 de diciembre de 1855, AMAE, Política Exterior, República Dominicana, legajo H 2374 (copia).
} 
cónsules europeos, particularmente el de España» era «muy fuerte». También se hizo eco del conflicto existente entre Santana y los tres cónsules por esta causa, y a continuación indicó que el presidente deseaba ceder algo más tarde la estación naval, aunque lo haría en ese mismo momento si el gobierno de Estados Unidos le asegurase que protegería a la República Dominicana de las consecuencias de dicho acto. Al final de su misiva, Elliot señaló que Santana estaba dispuesto a enfrentarse con España, e incluso lo habría hecho ya de no haber sido por Gran Bretaña y Francia, y predijo que en poco tiempo se producirían «graves dificultades» en la República Dominicana ${ }^{33}$.

En la segunda comunicación del 22 de marzo el agente comercial de Estados Unidos envió a Marcy dos copias del tratado dominicoespañol, y lo alertó sobre los artículos sexto y séptimo, pues en ellos se podía advertir que España estaba «buscando gobernar de nuevo» sobre Santo Domingo. Elliot informó con preocupación al secretario de Estado de que muchos dominicanos reclamaban «la protección española» bajo ese tratado. Por último, en su tercer despacho Elliot envió a Washington el texto del tratado recién firmado por los dos plenipotenciarios dominicanos junto con el norteamericano ${ }^{34}$.

A pesar de la insistencia con que el agente comercial de Estados Unidos trataba de que su gobierno se tomara un poco más de interés por los asuntos dominicanos, como subraya Jimenes, la administración de Franklin Pierce no escuchó a Elliot, que no consiguió mover al presidente a realizar «ninguna acción favorable al gobierno dominicano». En efecto, la omisión de la concesión de «importancia primordial» para Marcy, en el proyecto de tratado entre ambos países, que era sin duda el arrendamiento de una porción de terreno en Samaná, explica la completa indiferencia con que el secretario de Estado vio el rechazo de tal proyecto por parte del Senado norteamericano. De acuerdo con la opinión del mencionado autor, Marcy pensaba que «la ratificación de un tratado meramente comercial no era una contribución eficaz a la realización del «destino manifiesto»»» de su país. A este planteamiento hay que sumar otro hecho de gran importancia, según la tesis defendida por Jimenes, quien sostiene que en aquellos momentos Pierce y Marcy tenían los ojos puestos en Cuba, cuya adquisición se habían propuesto lograr, frente a la oposición de Gran Bretaña, Francia y por supuesto España, de modo que «consideraron inoportuno echar una brasa más a la encendida pugna entre Estados Unidos y dichas potencias». Entretanto, «las gestiones de Segovia siguieron su curso, con el firme y entusiasta apoyo del baecismo» ${ }^{35}$.

\footnotetext{
33 Lockward, 1987: 283.

34 Ibidem: 284.

35 Jimenes Grullón, 1980, vol. 1: 68-69. El autor cita a Welles, 1939, vol. 1: 166-170.
} 
En efecto, pese a que tenía instrucciones de obrar con la máxima cautela para no provocar un enfrentamiento abierto con el gobierno norteamericano, Segovia fue más lejos que sus colegas británico y francés, quienes se conformaban con impedir el arrendamiento de Samaná a Estados Unidos. Con la fuerza que le daban los cada vez más numerosos matriculados, baecistas en una gran parte, el cónsul de España presionó al ejecutivo dominicano para que los norteamericanos no obtuviesen la ansiada base naval, e incluso para que se les solicitara la devolución del tratado recién rubricado por ambos países. Segovia pretendía con ello cumplir estrictamente su misión de obstaculizar por todos los medios posibles el establecimiento de relaciones entre Washington y Santo Domingo, así como el aumento de la influencia estadounidense en la República Dominicana. Consiguió dicho objetivo, pero además puso a España frente a frente con Estados Unidos, al desmarcarse de la prudente diplomacia francobritánica e injerirse de forma tan directa en la política interna dominicana.

\section{LA POLÉMiCA DE LA MATRÍCULA CONSUlAR Y EL AUMENTO DE LA TENSIÓN

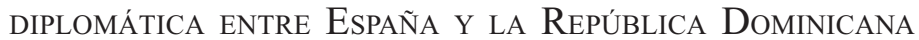

El cónsul Segovia ha pasado a formar parte de la historia dominicana, debido sobre todo a la controversia que se originó en torno a la interpretación de los límites establecidos por el artículo séptimo del tratado dominicoespañol de 1855 , con respecto a quiénes podían inscribirse como súbditos españoles en la matrícula consular abierta a tal efecto. Sin negar la actitud intervencionista de Segovia, admitida como algo evidente por todos los autores, no parece justificable la simplificación de esta polémica mediante su reducción a unos términos conceptualmente poco rigurosos.

Un ejemplo de ello es la interpretación de Balcácer y García Arévalo sobre este conflicto diplomático, cuando afirman lo siguiente: «Como las negociaciones con Estados Unidos no se detuvieron», se frustró la pretensión de Segovia de un protectorado español. Aquél «procedió entonces a la apertura de libros de registro en la sede del consulado para que todo el que deseara adoptar la nacionalidad española, así lo hiciese». A continuación, ambos autores indican que «Segovia fundamentó su proceder en una interpretación antojadiza del artículo VII del tratado de reconocimiento firmado en 1855 entre España y la República Dominicana» ${ }^{36}$.

\footnotetext{
${ }^{36}$ Balcácer y García Arévalo, 1992: 133.
} 
Lo cierto es que la indefinición en lo relativo a la nacionalidad de algunos residentes en este último país, que se declaraban españoles, ya venía arrastrándose desde hacía tiempo. Por ello habría que analizar, en primer lugar, si realmente el mencionado artículo del tratado era tan claro como requerían las circunstancias, o si, por el contrario, dejaba demasiado espacio a la libre interpretación de cada quien. Todo parece indicar que se trata más bien de esto último ${ }^{37}$.

Antes de abordar la cuestión, resulta pues necesario aproximarse en la medida de lo posible al contexto que originó la actuación más discutida de Segovia en el desempeño de sus funciones como cónsul de España en Santo Domingo, la cual terminó por costarle el puesto. Cabe preguntarse, empleando las palabras de Jimenes Grullón, qué factor o factores indujeron al cónsul de España a

producir lo que ha sido considerado con razón como la primera manifestación de abierto intervencionismo, por parte de una potencia foránea, en nuestra vida de Estado independiente, excepción hecha de las actuaciones del cónsul francés SaintDenis cuando el nuevo Estado nacía y en los meses inmediatamente posteriores ${ }^{38}$.

El propio Segovia dio la respuesta en una extensa comunicación enviada a Zabala, en la cual expresó abiertamente su disconformidad con respecto a algunos aspectos de la política seguida por España hacia aquella isla. El cónsul se sinceró hasta extremos poco frecuentes en un despacho de carácter oficial, lo que permite hacerse una idea más cabal de su pensamiento, que con relación a Haití era el siguiente:

Veo con tristeza que España lleva su mesura y consideración hasta el punto de seguir la marcha de Francia e Inglaterra en cuanto a guardar con el ridículo gobierno de Soulouque miramientos de que algún día tendrán que arrepentirse ${ }^{39}$.

Además, Segovia consideraba que «aun bajo el aspecto más egoísta de una política estrecha, la vecindad del imperio haitiano» era «siempre un grande inconveniente para la dueña de Cuba y Puerto Rico». Sin embargo, el aspecto que concierne más de cerca a este estudio es la opinión que merecía al diplomático español el régimen de Santana, sobre el cual aquél afirmó sin ambages:

\footnotetext{
${ }^{37}$ Para un estudio actualizado de la matrícula de Segovia, véase Julián, 2012: 71-86; así como, sobre los antecedentes de dicha cuestión, Escolano Giménez, 2011: 286-290.

${ }_{38}$ Jimenes Grullón, 1980, vol. 1: 68. El autor apoya su juicio en Alfau Durán, 1956: 186.

39 Carta de Segovia al ministro de Estado español, Santo Domingo, 22 de marzo de 1856, AMAE, Política Exterior, República Dominicana, legajo H 2374.
} 
Si volvemos los ojos a la [...] República Dominicana, lo que encontramos es la vera effigie de Soulouque en la persona del presidente Pedro Santana. La misma ignorancia, o por mejor decir, falta absoluta de las más sencillas nociones de la justicia y del derecho, los mismos instintos de tiranía, la misma falta de respeto a las naciones extranjeras con quienes le ligan los tratados. Orgulloso hasta rayar en la demencia por su último triunfo sobre los haitianos [...], despliega en el gobierno interior (ya convertido en dictadura declarada) toda la ferocidad de su carácter, y en cuanto a la política internacional trata con insulto y desprecio a sus mejores aliados. [...] Los agentes de Francia e Inglaterra [...] han elevado ya a sus respectivos gobiernos sentidas quejas, y están dispuestos a notificar oficialmente a Santana que la mediación se retira [...]. Para esto sólo aguardan a que sea un hecho consumado la aprobación del proyecto de tratado con los Estados Unidos ${ }^{40}$.

La obsesión de Segovia era por tanto eliminar a Santana de la escena política, a fin de impedir u obstaculizar el acercamiento entre los gobiernos dominicano y estadounidense. El cónsul de España fue a Santo Domingo precisamente con la misión de debilitar al máximo la influencia norteamericana en los asuntos de la isla, algo que se había propuesto cumplir a cualquier precio. En efecto, Segovia se vio obligado a utilizar procedimientos muy alejados de una exquisita neutralidad diplomática, que habría sido poco eficaz en aquellas circunstancias, como explicó al ministro de Estado, a quien hizo ver que tras la firma del tratado dominicoespañol, Santana «cambió enteramente de conducta, y se quitó aquella máscara de españolismo con que había sido retratado por sus agentes en Madrid», y esta circunstancia contribuyó «no poco tal vez [...] a la excesiva generosidad con que se redactaron las cláusulas» de dicho tratado ${ }^{41}$.

A partir de ese momento, el pensamiento de Santana «no fue otro que el de entregarse sin freno a sus tenebrosos tratos con el agente de Washington», por lo que el cónsul se propuso en primer lugar «emplear la persuasión [...] para convencer a Santana y a sus ministros de que el tratado» dominiconorteamericano «les era bajo más de un concepto perjudicial». En tal sentido, Segovia llamó la atención de aquéllos

sobre lo sospechosa que debía hacérseles la conducta de una nación que siendo grande, poderosa, fuerte [...] de repente cambia de actitud y viene a mendigar una y otra, y otra vez a Santo Domingo la conclusión de un tratado el más extenso, completo y solemne que puede imaginarse ${ }^{42}$.

Segovia insistió también al gobierno dominicano acerca de que si en esa negociación había «un fin o un interés político», Estados Unidos estaba obli-

\footnotetext{
${ }^{40}$ Idem (el texto en cursiva aparece subrayado en el documento).

${ }^{41}$ Idem.

42 Idem.
} 
gado a declararlo, de igual modo que las otras naciones habían declarado los objetivos de sus respectivos pactos con la República Dominicana. El diplomático añadió de forma tajante que «si ese interés político no se confiesa altamente, prueba de que es bastardo y sospechoso», y concluyó con estas palabras: "Que el interés sea meramente comercial lo desmiente el hecho de que las relaciones mercantiles entre ambos países son insignificantes» ${ }^{43}$.

Con respecto a este último punto, cabe señalar que la actividad importadora-exportadora de la República Dominicana era un monopolio de los grandes comerciantes extranjeros, en su mayoría de origen europeo. Además de dedicarse al comercio, muchos de ellos también poseían cortes de madera, por ejemplo Abraham Coen, representante de la casa Rothschild y Coen, a quien Cassá considera, «sin duda, el hombre más rico del país» en esos momentos. En efecto, las exportaciones dominicanas durante este período se basaban de modo casi exclusivo en dos productos, uno en declive y otro en plena expansión. El primero de ellos lo constituían las maderas preciosas, principalmente caoba, de la cual en 1855 se exportaron 3.479 .000 pies, cifra que según Cassá «indica ya una tendencia al estancamiento decreciente». En cuanto al valor de dicha mercancía, de acuerdo con los datos proporcionados por el cónsul de Gran Bretaña en Santo Domingo, en ese mismo año se exportaron por el puerto de la capital dominicana 2.600 .000 pies que, «a un promedio de 122 pesos fuertes cada millar, da una suma total de 320.245 pesos fuertes». Cassá estima que las exportaciones de caoba pudieron superar en 1855 el medio millón de pesos fuertes, ya que esta madera también se embarcaba desde los puertos de Azua y Samaná ${ }^{44}$.

Esta producción se destinaba casi por completo a los mercados europeos, y lo mismo sucedía con la otra gran actividad comercial, el cultivo de tabaco, producto del cual en 1856 se vendieron 55.000 quintales en el exterior, mediante intermediarios de las casas importadoras, radicadas sobre todo en Hamburgo y Bremen. El precio del tabaco fluctuaba más que el de la caoba, pues en él «intervenía el factor de la calidad específica de la cosecha», pero en general se trataba de un tabaco «de mala calidad, por lo que los precios que recibía el país eran muy bajos». Así pues, mientras que en 1847 el quintal se pagaba a un promedio de 5,33 pesos fuertes, en 1853 ese promedio subió

${ }^{43}$ Idem.

${ }^{44}$ Cassá, 1998, vol. 2: 16-18. Si bien el autor sólo menciona como unidad de medida el «pie», cabe pensar que estas cantidades deben referirse al volumen de la madera exportada. En caso de tratarse del pie-tabla o pie tablar, éste equivale a un pie de ancho por un pie de largo por una pulgada de espesor. En el caso del pie cúbico, dicha unidad equivale al volumen de un cubo de un pie de lado. 
hasta 7 pesos fuertes ${ }^{45}$. A la luz de estos datos puede deducirse que el intercambio comercial con Estados Unidos se mantenía en unos niveles bastante bajos, tal como señaló Segovia.

El cónsul de España sostuvo que sus razonamientos habían convencido «a algunos miembros del gabinete de Santana, pero no a los otros cohechados ya de antemano, y mucho menos a Santana mismo, en cuyo obtuso entendimiento» no hacían mella «el raciocinio ni la dialéctica». En vista del poco éxito de los argumentos esgrimidos, Segovia advirtió al presidente del «peligro a que se exponía descontentando a Francia y a Inglaterra». Por otra parte, el cónsul presionó a Zabala con el argumento de que, puesto que España tenía «el mismo y aun mayor interés en oponerse» a un acercamiento entre la República Dominicana y Estados Unidos, y estaba «resuelta a seguir en la Isla Española la política de sus aliadas», debería asociarse también a las medidas de rigor que se tomasen contra Santana, a quien calificó de «hombre ciego e ingrato». Acto seguido, Segovia matizó que de esta acusación había que salvar no sólo a algunos de sus ministros, sino «al pueblo en general, cuyo espíritu» era, en su opinión, «español», pero censuró la actuación de las principales figuras del régimen santanista en unos términos muy duros:

Resumiendo lo relativo al tratado [...]: el proyecto se fraguó mal y de mala manera por los plenipotenciarios que fueron por parte de los E. U. su agente comercial en Santo Domingo, y por parte de esta República el Sr. Castro [...] y el mulato, presidente del Senado, Tomás Bobadilla: este último es uno de los malos genios de Santana, su consejero en todas las sangrientas ejecuciones y asesinatos jurídicos [...] que ha sabido granjearse el odio popular; si bien comparte esta ventaja con el ministro de Hacienda D. Manuel Delmonte. Ambos son enemigos declarados de España, y partidarios acérrimos de los E. U.

[...]. El proyecto se pasó al Senado, donde atropelladamente [...] los siete esclavos mudos que aquí se llaman senadores dieron por aprobado el documento, no ya sin meditarlo, pero aun sin leerlo por sí mismos ${ }^{46}$.

Segovia dio por supuesto que los hechos ya descritos eran motivo más que suficiente para que el gobierno español considerase a Santana «como su enemigo capital [...] y como un grande embarazo para la conservación» de Cuba y Puerto Rico. Sin embargo, todavía quedaba lo peor de este «catálogo de agravios», pues una vez abierta la matrícula de españoles en el consulado,

${ }^{45}$ Ibidem: 19-23.

${ }^{46}$ Carta de Segovia al ministro de Estado español, Santo Domingo, 22 de marzo de 1856, AMAE, Política Exterior, República Dominicana, legajo H 2374. 
«y cuando apenas llegaban a una docena el número de los individuos que siendo naturalizados dominicanos» habían optado en virtud del artículo séptimo por la nacionalidad española, «Santana se alarmó, bajo pretexto de que según se manifestaba el espíritu público, la mitad de la población se haría española». Ante este nuevo contratiempo, Segovia trató de calmar los ánimos y de hacer ver al gobierno que sus temores eran completamente infundados, puesto que «de hecho no sucedía así», y sólo unos pocos ciudadanos hasta ese momento tenidos por dominicanos se habían inscrito como españoles. En segundo lugar, señaló que «no era presumible que tan crecido número de individuos se determinase a adoptar la calidad de extranjero en su propio país», pero sin atender a tales planteamientos, Santana ordenó «encarcelar y perseguir a los matriculados y a cuantos se matriculasen», como sucedió en algún caso $^{47}$.

En una situación tan compleja, el agente decidió no responder con una protesta, por temor a que en Madrid no se creyera «este cambio de conducta sin grandes explicaciones», y recurrió a «los medios conciliatorios, suspendiendo la matrícula [...], y exigiendo imperiosamente que los presos fuesen puestos en libertad, como así fue». Segovia intentó poner término a la cuestión de la matrícula, por lo menos de forma provisional, y quiso «enseguida anunciar al público la suspensión» de la misma, pero el gobierno dominicano se lo prohibía mientras no suprimiese de dicho anuncio «la idea de que la duda ocurrida sobre el tratado» no era suya, sino de las autoridades dominicanas. El diplomático consideraba que «habría bajeza en ceder hasta ese punto», por lo cual se resistió a «toda corrección» ${ }^{48}$. En efecto, el cónsul de España en Santo Domingo solicitó al ministro dominicano de Relaciones Exteriores que ordenara insertar en la Gaceta un aviso redactado por el propio Segovia, para hacer pública la suspensión de la matrícula en la legación española ${ }^{49}$.

El artículo séptimo del tratado, que había originado la polémica, estipulaba lo siguiente:

Convienen ambas partes contratantes en que aquellos españoles que, por cualquier motivo, hayan residido en la República Dominicana, y adoptado aquella nacionalidad, podrán recobrar la suya primitiva, si así les conviniese, en cuyo caso sus hijos mayores de edad tendrán el mismo derecho de opción; y los menores,

${ }^{47}$ Idem.

${ }^{48}$ Idem.

49 Carta de Segovia al ministro de Relaciones Exteriores dominicano, Santo Domingo, 17 de marzo de 1856, Archivo General de la Nación (AGN), Santo Domingo, Relaciones Exteriores, legajo 9, exp. 10. 
mientras lo sean, seguirán la nacionalidad del padre, aunque unos y otros hayan nacido en el territorio de la República.

El plazo para la opción será el de un año respecto de los que existan en el territorio de la República, y dos para los que se hallen ausentes. No haciéndose la opción en este término, se entiende definitivamente adoptada la nacionalidad de la República.

Convienen igualmente en que los actuales súbditos españoles, nacidos en el territorio de Santo Domingo, podrán adquirir la nacionalidad de dicha República, siempre que, en los mismos términos establecidos en este artículo, opten por ella. En tales casos sus hijos mayores de edad adquirirán también igual derecho de opción; y los menores, mientras lo sean, seguirán la nacionalidad del padre.

Para adoptar la nacionalidad será preciso que los interesados se hagan inscribir en la matrícula de nacionales, que deberán establecer las legaciones y consulados de ambos Estados; y transcurrido el término que queda prefijado, sólo se considerarán súbditos españoles y ciudadanos de la República Dominicana los que, procedentes de España y de dicha República, lleven pasaportes de sus respectivas autoridades, y se hagan inscribir en el registro o matrícula de la legación o consulado de su nación ${ }^{50}$.

Sin embargo, poco después de su suspensión, Segovia volvió a abrir la matrícula consular, en la que, de acuerdo con la interpretación de García, se inscribía «indistintamente a dominicanos cuyos padres no tuvieron nunca derechos de españoles, y a extranjeros súbditos de distintas nacionalidades». Este autor transmite asimismo la información recogida en un «documento oficial de la época», el cual indicaba que fue en vano que el gobierno dominicano presentase a Segovia los derechos de la República y «el perjuicio que causaba a ésta la abusiva extensión dada a la matrícula», así como «el embarazo que se creaba a España misma con la formación de una colonia de pseudoespañoles, origen y ocasión de conflictos y reyertas dondequiera». También fue en vano que la autoridad de los cónsules de Francia y Gran Bretaña «se interpusiera para impedir, o siquiera atenuar, tan monstruoso y escandaloso abuso» ${ }^{51}$.

El citado documento señalaba que el gobierno dominicano podía escoger entre dos opciones, ambas legales y legítimas: la primera consistía en impedir que Segovia «llevara a efecto, por sí y ante sí, con anuencia o no» del gobierno

50 Tratado de reconocimiento, paz, amistad, comercio, navegación y extradición entre $S$. M. la reina de España y la República Dominicana, Madrid, 1855, AMAE, Política Exterior, República Dominicana, legajo H 2374.

${ }^{51}$ García, 1968, vol. 3: 179. 
español, pero sin participación del dominicano, «la interpretación de una cláusula de tratado entre partes, y la material aplicación de su voluntarioso comentario»». Para una cosa y otra se requería «una interpretación auténtica, convenida [...] por ambas partes contratantes». En ausencia de dicho acuerdo, «y en caso de insistencia por parte del agente español, el gobierno dominicano estaba competentemente autorizado para suspender con él toda especie de relaciones», e incluso para expulsarlo del territorio de la República ${ }^{52}$.

La segunda vía posible era acudir al gobierno español por medio del representante del ejecutivo de Santo Domingo en Madrid, como también recoge García, «pidiendo una aclaración del artículo $7^{\circ}$ negociada según los trámites ordinarios en asuntos de tal naturaleza» ${ }^{53}$, que fue el camino escogido por el gobierno dominicano para resolver la polémica cuestión suscitada por Segovia. En la decisión de éste de reabrir la matrícula es probable que influyera la aprobación por el Senado Consultor, en todas sus partes, del tratado de paz, comercio, navegación y extradición entre la República Dominicana y Estados Unidos.

Con respecto a dicho tratado, pero sin conocer todavía la noticia de su aprobación, Zabala se dirigió al representante de España en París, a fin de comunicarle que el ejecutivo de Madrid no había dudado nunca de la cooperación eficaz que Gran Bretaña y Francia estaban dispuestas a prestarle «contra la celebración de un tratado de alianza» entre Estados Unidos y la República Dominicana. Sin embargo, pese a la confianza que el ministro de Estado tenía en ese punto, aún se podía «recelar que a la sombra, y con el pretexto de un pacto comercial», se favoreciera de tal modo a la Unión, que el tratado redundase en perjuicio de los intereses coloniales españoles. Por este motivo, Zabala insistió en la conveniencia de estar muy pendientes de un asunto tan importante para España, y que no era «digno de descuido tampoco» para Francia ni Gran Bretaña ${ }^{54}$.

\section{Respuesta de las autoridades españolas fRente al agraVAmiEnto de la SITUACIÓN DOMINICANA}

El 15 de marzo Segovia informó al agente de España en Washington, Alfonso de Escalante, de la próxima aprobación del tratado dominicoestadouni-

${ }^{52}$ Idem.

${ }^{53}$ Ibidem: 179-180.

${ }^{54}$ Carta de Zabala al ministro plenipotenciario de España en París, Madrid, 6 de abril de 1856, AMAE, Política Exterior, República Dominicana, legajo H 2374 (minuta). 
dense. Tras conocer el hecho, Segovia se había reunido con los representantes de Gran Bretaña y Francia para intentar llegar a algún tipo de acuerdo con relación a la política que debían seguir en tal asunto, pero ambos diplomáticos propusieron esperar hasta recibir instrucciones de sus respectivos gobiernos, y entonces adoptarían la decisión más oportuna. Escalante transmitió estas noticias a Zabala y añadió: «Las funestas consecuencias que acarrearía» a Cuba el hecho de que Estados Unidos llegase a «influir poderosamente» en Santo Domingo, «o a poner el pie en Samaná lo dejo a la consideración del gobierno de S. M». En el despacho puede leerse una anotación fechada en el Ministerio de Estado el 10 de mayo de 1856, en la cual se indicaba la necesidad de instruir al plenipotenciario de España en Washington para que, de acuerdo con los agentes de Francia y Gran Bretaña en esa capital, gestionase «la no ratificación del tratado». Dicha anotación señalaba asimismo que debían ponerse en conocimiento de Escalante las consideraciones dirigidas al gobernador de Cuba y al cónsul de España en Santo Domingo ${ }^{55}$.

Esas consideraciones las hizo el general O'Donnell, ministro de la Guerra, en nombre de su colega de Estado, quien se encontraba ausente de Madrid, y en ellas se advierte una mayor determinación ante los graves acontecimientos que tenían lugar en la República Dominicana, sobre todo con respecto a la matrícula. O'Donnell comunicó a Segovia, en relación con el tratado dominiconorteamericano, que se trataba de un asunto cuyas negociaciones habían «seguido desde un principio mancomunadamente España, Francia e Inglaterra, en el que por consiguiente» era «indispensable proceder de acuerdo para reunir la acción combinada de las tres potencias». Por ello, O’Donnell se había dirigido también a los embajadores de España en París y Londres, a fin de que procurasen persuadir por todos los medios a los gobiernos francés y británico acerca

de la imperiosa necesidad que existe de que las tres naciones reunidas tomen una actitud más decidida, enérgica e imponente en Santo Domingo, tanto para impedir la ratificación del tratado con los Estados Unidos, si aún fuera tiempo, como para anular o desvirtuar en parte o en todo sus efectos, y tener en respeto a Santana ${ }^{56}$.

En lo relativo al segundo punto de fricción entre Segovia y el gobierno dominicano -la matrícula consular-, las instrucciones no dejaban lugar a dudas. Así, O’Donnell calificó la cuestión como «de interés y de decoro esencial-

${ }_{55}$ Carta de Escalante al ministro de Estado español, Washington, 15 de abril de 1856, AMAE, Política Exterior, República Dominicana, legajo H 2374.

${ }_{56}$ Carta de O'Donnell al cónsul de España en Santo Domingo, Madrid, 6 de mayo de 1856, AMAE, Política Exterior, República Dominicana, legajo H 2374 (minuta). 
mente» españoles, y comunicó a Segovia las órdenes que había transmitido al gobernador de Cuba, que consistían en enviar a Santo Domingo «dos buques de guerra o cuando menos uno de gran porte, para sostener con eficacia [...] las reclamaciones» del cónsul de España ante el gobierno dominicano. Por ello, el ministro indicó a Segovia que debía abstenerse de dirigirle protesta alguna hasta que llegaran a esas aguas las mencionadas fuerzas navales. Una vez allí, y puesto de acuerdo con su comandante, O’Donnell señaló al diplomático los siguientes pasos que debía dar:

Dirigirá una sentida y enérgica reclamación al gobierno de esa República exigiendo una satisfacción completa [...] por el atentado cometido contra los súbditos españoles que fueron perseguidos y encarcelados con motivo de haberse inscrito en las matrículas de ese consulado [...].

Exigirá V. S. además de ese gobierno una declaración formal y suficiente de que se halla dispuesto a cumplir religiosamente en todos y cada uno de sus artículos, con arreglo al espíritu y letra de los mismos, el tratado de 18 de febrero de 1855.

A continuación y sin ulterior demora procederá V. S. a inscribir en las matrículas de ese consulado a todos aquellos españoles que según lo estipulado en el artículo $7^{\circ}$ del tratado, tengan derecho a obtener o recobrar la nacionalidad española ${ }^{57}$.

El ministro de la Guerra adelantó también cuál debía ser la respuesta en caso de que Santana «se negase a dar la satisfacción exigida, o lo difiriese con pretextos frívolos», o tratara de poner impedimentos a la matriculación de los españoles. En tal circunstancia, Segovia tendría a su disposición los barcos de la Armada «para sostener con eficacia y energía sus reclamaciones», hasta que el asunto estuviera «completa y satisfactoriamente terminado». Acto seguido, O’Donnell explicó al cónsul que el principal objetivo del gobierno español, al enviar estas fuerzas navales, era «obtener satisfacción cumplida por los agravios inferidos» a los ciudadanos españoles, así como «restablecer de una vez para siempre el imperio del tratado». Además, el ministro de la Guerra esperaba que Segovia supiese «aprovechar esta oportunidad para asegurar la influencia española en ese país de un modo sólido y eficaz», que diera «completas garantías para el porvenir». O’Donnell afirmó que el gobierno español creía «llegado el caso de hacer una demostración de fuerza» en la República Dominicana, si el gobierno de ésta no accedía a las reclamaciones de su representante, y recomendó a Segovia que no omitiera medio alguno para defender el prestigio de España si la situación llegase al extremo ${ }^{58}$.

\footnotetext{
57 Idem.

58 Idem.
} 
O’Donnell envió a los plenipotenciarios de España en Londres y París una copia del despacho anterior, para ponerlos «al corriente del nuevo y grave aspecto» que había tomado la situación en la República Dominicana. Aquél también les dio instrucciones, en el sentido de «llamar muy especialmente y sin pérdida de tiempo la atención» de los respectivos ministros de Asuntos Exteriores sobre el particular. Debían insistir en que España estaba dispuesta a secundar los proyectos y medios que Francia y Gran Bretaña juzgaran necesario emplear, así como en la idea de que «los perjuicios que se seguirían a las tres naciones si los angloamericanos consiguiesen establecer su predominio y aun su influencia en la Isla Española» eran evidentes. Por ello, la simple sospecha de que pudiera acontecer algo así hizo que el gobierno español autorizase a sus representantes diplomáticos a entrar en conversaciones con los gobiernos de ambos países, a fin de concertar los medios más convenientes para «destruir los proyectos presentes y futuros» de Estados Unidos. Finalmente, O'Donnell les indicó que informaran asimismo a dichos gobiernos de las medidas adoptadas por España con respecto a la cuestión de la matrícula consular, y de los motivos que las habían hecho imprescindibles ${ }^{59}$.

En respuesta al ministro de Estado, Antonio González, agente de España en Londres, resumió su entrevista con Clarendon, en la cual le había expuesto la necesidad de poner obstáculos a la ratificación del tratado dominiconorteamericano. El diplomático español le había hecho notar además «la eficacia del gobierno de la Confederación para insistir en la celebración de un tratado con una República insignificante», pero que estaba muy próxima a Cuba, adonde dirigía aquel gobierno «sus pretensiones interesadas». A pesar de los argumentos esgrimidos por González, el jefe del Foreign Office le manifestó que el asunto del tratado estaba ya muy adelantado y era «difícil encontrar medios legítimos para impedir su consumación o ratificación». Dado que el mismo se limitaba «meramente a relaciones mercantiles», no se podía impedir que ningún estado estableciera los pactos que estimase oportunos para fomentar sus intereses. A continuación, el ministro británico añadió que «si se tratara de alianza u otras relaciones políticas, como en otras épocas», se emplearían en tal caso, de acuerdo con los gobiernos de España y Francia, «los medios conducentes para impedirlo» ${ }^{60}$.

En cuanto a la cuestión de la matrícula, Clarendon consideró justo el procedimiento concebido por el gobierno español, pero preguntó al embajador qué

${ }_{59}$ Carta de O'Donnell a los ministros plenipotenciarios de España en París y Londres, 6 de mayo de 1856, AMAE, Política Exterior, República Dominicana, legajo H 2374 (minuta).

${ }_{60}$ Carta de González al ministro de Estado español, Londres, 15 de mayo de 1856, AMAE, Política Exterior, República Dominicana, legajo H 2374. 
haría el ejecutivo de Madrid en caso de que el de Santo Domingo no satisficiese sus demandas, a lo cual González repuso que el gobierno español tenía «fuerza para exigir una justa reparación», aunque esperaba que la respuesta de Santana no diera motivo para utilizarla ${ }^{61}$.

González mostró su acuerdo con la apreciación de Clarendon acerca del tratado dominiconorteamericano, al considerar él también que este asunto se encontraba muy adelantado. Acto seguido, el embajador hizo un comentario sobre las tensiones entre Gran Bretaña y Estados Unidos, y citó las dudas a que había dado lugar el tratado Clayton-Bulwer, lo cual coadyuvaba también a entender la prudente actitud británica en torno a la conflictiva coyuntura dominicana. El agente de España en Londres se vio obligado a señalar a Zabala que, en esas circunstancias, era difícil para el ejecutivo de Madrid «influir eficazmente en una resolución» para que no se ratificase el tratado, y añadió que el enfrentamiento entre Segovia y el gobierno dominicano privaba a aquél «de la legítima influencia para impedir la ratificación del tratado por el presidente Santana». Al final de su despacho, González lanzó una velada crítica hacia la actuación del gobierno español y, sobre todo, de su representante en Santo Domingo, cuando afirmó:

Si oportunamente se hubieran empleado los medios para impedir la negociación, sin duda alguna se hubiera obtenido buen resultado; pero hoy es muy difícil impedir la ratificación ${ }^{62}$.

El tratado Clayton-Bulwer fue suscrito entre Estados Unidos y Gran Bretaña en 1850, a fin de prohibir la creación de un canal interoceánico y la soberanía de cualquiera de esos dos países en Centroamérica. Con ello se pretendía preservar el statu quo en un área de tanta importancia geoestratégica, equilibrio que ponían en peligro las expediciones de algunos aventureros norteamericanos, como Walker y Kinney.

Por consiguiente, cabe hablar de una nueva actitud británica frente a Estados Unidos, motivada ante todo por los intereses económicos, puesto que tanto el Foreign Office como la prensa opinaban, según recoge Hauch, que «el mejor modo de lograr algo era abandonar su actitud hostil a la expansión norteamericana» hacia el sur. Aunque el gobierno británico no reconocía el derecho de Estados Unidos «al monopolio en ese campo, ni la validez de la doctrina Monroe», a juicio de dicho autor el ejecutivo de Londres no se opondría ya de una «manera activa a lo que muchos ingleses consideraban un empuje inevitable» ${ }^{63}$.
61 Idem.
62 Idem.
63 Hauch, 1996: 123. 
Existen también otros factores que explican lo que Hauch denomina «retroceso» en la nueva política desarrollada por Gran Bretaña. En primer lugar, el ejecutivo de Londres dejó de temer que Estados Unidos hubiera decidido excluir a los comerciantes e inversores británicos de América Latina. Por otra parte, Gran Bretaña «se beneficiaría económicamente de la estabilidad política y las oportunidades de inversión que el control norteamericano brindase» en aquellas naciones y, en definitiva, «los lazos británicos de intercambio e inversión con Estados Unidos eran mucho más valiosos» que los que mantenía con los demás países de ese hemisferio. Así pues, resultaba poco inteligente arriesgarse a una guerra anglonorteamericana que, en opinión del mencionado autor, «suspendería temporalmente y quizás perjudicaría para siempre las relaciones económicas» entre ambas potencias, y todo ello "sin garantía de compensación inmediata en los trópicos» ${ }^{64}$.

Finalmente, Hauch también subraya el hecho de que la posibilidad de que Estados Unidos continuara su expansión hacia el sur se fue reduciendo a partir de 1856. En efecto, la creciente agitación de los esclavos obligaba a muchos habitantes de los estados del norte a ver los proyectos de expansión hacia el sur «como complots esclavistas para obtener un lebensraum para la odiada institución». Sin embargo, este autor sostiene que «la creciente parálisis» del gobierno de Washington tardó bastante tiempo en hacerse evidente para el de Londres, que pensaba que su recién adoptada postura «era esencial para evitar complicaciones» con Estados Unidos ${ }^{65}$.

Por su parte, Salustiano de Olózaga, representante de España en París, comunicó al ministro de Estado que la información transmitida por O’Donnell el 6 de mayo confirmaba los temores que él tenía «desde que se reconoció la independencia de la República de Santo Domingo». Olózaga había puesto los hechos en conocimiento del ministro francés de Asuntos Extranjeros, que reconoció las razones del gobierno español «para proceder con toda energía» frente al dominicano. Walewski le prometió que en las instrucciones que iba a extender al nuevo cónsul de Francia en Santo Domingo le indicaría que se pusiera de acuerdo con el cónsul de España, y lo apoyase «en todas sus gestiones». Sin embargo, según el diplomático español, Walewski «no se mostró tan seguro» con relación al tratado entre la República Dominicana y Estados Unidos, ya que Clarendon lo había convencido de que el mismo sólo contenía «estipulaciones puramente comerciales» ${ }^{66}$.

64 Idem.

${ }^{65}$ Idem.

${ }^{66}$ Carta de Olózaga al ministro de Estado español, París, 16 de mayo de 1856, AMAE, Política Exterior, República Dominicana, legajo H 2374. 
El ministro francés había confesado a Olózaga que «no estaba tan bien informado» como en otras ocasiones sobre lo que pasaba en la República Dominicana, lo cual para el agente de España en París podía ser una explicación de por qué no se había enviado aún al nuevo cónsul de Francia en Santo Domingo. Además de todo lo expuesto, Olózaga mencionó como un factor negativo para los intereses españoles en las Antillas que el estado de las relaciones entre los gabinetes de Londres y Washington fuera «tan delicado». A ello se sumaba que el deseo del gobierno francés «de proceder en todas las cuestiones de acuerdo con el británico» fuese tan grande y tan sincero, por lo que el diplomático español temía que no se tomara «una decisión tan pronta y tan enérgica» como el caso parecía requerir ${ }^{67}$.

A pesar de los obstáculos que dificultaban el diseño de una política común por parte de las tres potencias europeas, Walewski quiso tranquilizar al ejecutivo de Madrid, y aseguró a Olózaga que Francia daría «órdenes bien explícitas y terminantes para que si se hubiera tratado de alguna cesión de territorio de la República de Santo Domingo» a Estados Unidos, se procurase «impedir, o al menos suspender la ejecución de semejante acto». El representante de España en París concluyó en un tono algo escéptico, ya que consideraba que las seguridades que el ministro le había dado eran provisionales, y siempre supeditadas a la condición de «evitar todo conflicto con el gobierno de Washington», hasta que los de París y Londres llegasen a un acuerdo sobre la decisión más conveniente al respecto ${ }^{68}$.

El gobierno español se encontraba, pues, cada vez más solo en su estrategia preventiva ante la amenaza de un tratado cuyo contenido aún no conocía, pero que no dejaba de preocuparle. El agente de España en Londres volvió a reunirse el 27 de mayo con Clarendon, a quien planteó que aunque el tratado fuese estrictamente comercial, se podían «anular sus efectos comerciales y cualquiera tendencia política» mediante una actuación conjunta de Gran Bretaña, Francia y España, a fin de alcanzar un acuerdo equivalente con la República Dominicana, «para estar siempre a la vista y en observación de la conducta del gobierno de la Unión». González sólo obtuvo de este encuentro un vago compromiso por parte de Clarendon, en el sentido de llevar a cabo dicho plan de acuerdo con Francia y España, cuando se conociera oficialmente el contenido del tratado dominiconorteamericano. Con más optimismo que realismo, el diplomático español afirmó que se había avanzado mucho, y que el ejecutivo de Madrid podía «contar en esta importante cuestión con la

\footnotetext{
67 Idem.

68 Idem.
} 
cooperación» del de Londres, «para detener la política ambiciosa del gabinete de Washington en un punto tan próximo a la isla de Cuba» ${ }^{69}$.

El representante de España en la capital británica parecía confundir la realidad de los hechos con sus propios deseos, pues los tiempos habían cambiado irremediablemente, y con ellos la política de alianzas, que estaba dictada cada vez en mayor medida por el pragmatismo de los intereses comerciales y económicos.

\section{Conclusiones}

Mientras tanto, en la República Dominicana se gestaba ya un asalto al poder muy ligado a las fuerzas actuantes en el plano internacional, y particularmente a la injerencia del cónsul de España en Santo Domingo. Ello hizo despertar la alarma entre sus colegas europeos, quienes recelaron de esa actuación, hasta el punto de que los gobiernos francés y británico presionaron al español para que pusiera fin a la agresiva política desplegada por su agente en Santo Domingo, la cual amenazaba con desplazarlos a un lugar secundario dentro del escenario dominicano, algo que no estaban dispuestos a consentir.

Las justas quejas del gobierno dominicano no podían ocultar que la polémica intervención de Segovia se sirvió del enorme descontento existente en buena parte de la sociedad, debido a las difíciles condiciones políticas y económicas del país. La injerencia del cónsul de España provocó que el ejecutivo de Santo Domingo solicitase al de Washington la devolución del tratado entre ambos países, así como la caída de Santana en mayo de 1856, quien fue sustituido por el vicepresidente Manuel de Regla Mota. Tras dimitir en septiembre de ese año, el general Alfau dejó vacante la vicepresidencia, para la cual resultó elegido Báez, quien accedió al cargo el 6 de octubre y tres días más tarde ocupó automáticamente la presidencia, pues Mota también dimitió. Sin embargo, todos estos «éxitos» no impidieron la destitución de Segovia, puesto que se había extralimitado en sus funciones, en las que cesó a finales de febrero de 1857.

Mediante un gesto tan conciliador, el ejecutivo de Madrid, que no tenía el menor deseo de enemistarse con sus dos principales aliados, maniobró de forma mucho más prudente con relación a la República Dominicana, es decir, hacia una política de nuevo en sintonía absoluta con las de Gran Bretaña y

${ }^{69}$ Carta de González al ministro de Estado español, Londres, 30 de mayo de 1856, AMAE, Política Exterior, República Dominicana, legajo H 2374 (el texto en cursiva aparece subrayado en el documento). 
Francia. En cualquier caso, esto fue así hasta que el cambio de la coyuntura internacional permitió de nuevo una presencia española más ambiciosa y decidida en el plano exterior, como la desarrollada por el gobierno de la Unión Liberal a partir de 1858, que desembocó en la fallida anexión de Santo Domingo a España (1861-1865) ${ }^{70}$. El fracaso de la experiencia anexionista, tras la insurrección generalizada del pueblo dominicano contra el dominio español a partir de agosto de 1863, coadyuvó al estallido de sendos levantamientos en Cuba y Puerto Rico, así como a la agudización de la rivalidad hispanoestadounidense en el área del Caribe.

\section{BiBLIOGRAFÍA}

Alfau Durán, Vetilio, "Centenario de la matrícula de Segovia. Inicio del intervencionismo en Santo Domingo", Clío, XXIV/108 (Santo Domingo, septiembre-diciembre 1956): 186-192.

Balcácer, Juan Daniel y García Arévalo, Manuel A., La independencia dominicana, Madrid, Mapfre, 1992. Colección Independencia de Iberoamérica, 7.

Cassá, Roberto, Historia social y económica de la República Dominicana, Santo Domingo, Alfa \& Omega, 1998.

Escolano Giménez, Luis Alfonso, "El comienzo de las relaciones diplomáticas entre España y la República Dominicana en 1855", Revista Complutense de Historia de América, 37 (Madrid, 2011): 277-299.

Escolano Giménez, Luis Alfonso, La rivalidad internacional por la República Dominicana y el complejo proceso de su anexión a España (1858-1865), Santo Domingo, Editora Mediabyte, 2013. Archivo General de la Nación, vol. CXCI.

Gándara Navarro, José de la, Anexión y guerra de Santo Domingo, Santo Domingo, Editora de Santo Domingo, 1975. [Facsímil de la primera edición: Madrid, El Correo Militar, 1884].

García, José Gabriel, Compendio de la historia de Santo Domingo, Santo Domingo, Publicaciones ¡Ahora!, 1968.

Hauch, Charles Christian, La República Dominicana y sus relaciones exteriores 18441882, Santo Domingo, Sociedad Dominicana de Bibliófilos, 1996.

Hungría Morell, Radhamés, "La batalla de Las Carreras: victoria decisiva de las armas dominicanas" (primera parte), Historia y Geografia, I/1 (Santo Domingo, 1982): 39-46.

\footnotetext{
${ }^{70}$ Para ampliar acerca de este período, véase: Escolano, 2013.
} 
Incháustegui Cabral, Joaquín Marino, Historia dominicana 1844-1930, Santo Domingo, [sin editorial], 1965.

Jimenes Grullón, Juan Isidro, Sociología politica dominicana 1844-1966, Santo Domingo, Taller, 1980.

Julián, Amadeo, "Rafael María Baralt. Su vida, obras y servicios prestados a la República Dominicana”, Clío, LXXXI/183 (Santo Domingo, enero-junio 2012): 43-125.

Lockward, Alfonso, Documentos para la historia de las relaciones dominico-americanas (1837-1860), Santo Domingo, Corripio, 1987.

Moya Pons, Frank, The Dominican Republic, a national history, Princeton (New Jersey), Markus Wiener Publishers, 1998.

Welles, Sumner, La viña de Naboth. La República Dominicana 1844-1924, Santo Domingo, Taller, 1981. [Primera edición en español: Santiago de los Caballeros, El Diario, 1939].

Fecha de recepción: 25 de mayo de 2013.

Fecha de envío de las modificaciones: 1 de marzo de 2014.

Fecha de aceptación: 5 de marzo de 2014.

\section{The Beginning of International Rivalry and Spanish Interference in the Dominican Republic (1855-1856)}

This study analyses the complex situation that the Dominican Republic experienced, resulting from the threat of Haiti, which once again invaded the Dominican Republic in 1855, as well as other more subtle interferences made by Great Britain, France, Spain and the United States. Diplomatic documentation of these two countries, along with bibliographic sources, have been used to investigate the beginning of foreign intervention in the Dominican Republic. The study of this process leads to the conclusion that the interference in Dominican politics by the First Consul of Spain in Santo Domingo helped accentuate Spanish-American rivalry.

KeY words: Interference in the Dominican Republic; Dominican Republic Foreign Relations; Dominican-Haitian War (1855-1856). 